\title{
Solar Panels Cleaning Frequency for Maximum Financial Profit
}

\author{
Mohammad Abu-Naser \\ Electrical Engineering Department, Philadelphia University, Amman, Jordan \\ Email: mabunaser10@gmail.com
}

How to cite this paper: Abu-Naser, M. (2017) Solar Panels Cleaning Frequency for Maximum Financial Profit. Open Journal of Energy Efficiency, 6, 80-86. https://doi.org/10.4236/ojee.2017.63006

Received: March 23, 2017

Accepted: August 8, 2017

Published: August 11, 2017

Copyright (C) 2017 by author and Scientific Research Publishing Inc. This work is licensed under the Creative Commons Attribution International License (CC BY 4.0).

http://creativecommons.org/licenses/by/4.0/

\begin{abstract}
Allowing the dust to accumulate on solar panels without adequate cleaning leads to huge monetary losses. Proper judgment of when to call for washing of solar panels is a compromise between gross costs of cleaning the panels and how much reduction in efficiency of solar panels can be tolerated. In this paper, we derive a formula for the optimal number of days between cleaning cycles of a solar array by minimizing the cost of cleaning the array and the lost revenue from the unclean panels. The formula will aid in deciding cleaning periods based on the environment in which the solar panels are installed and cost incurred from undertaking the washing process.
\end{abstract}

\section{Keywords}

Dust Deposition, PV Efficiency Degradation, Optimal Cleaning Cycle

\section{Introduction}

There is an established body of literature on the effect of dust on solar panel performance and efficiency. However, the literature on the frequency of cleaning solar panels from accumulated dust is limited.

One of the first rigorous experimental studies on the effect of dust on the I-V characteristic curve was conducted by El-Shobokshy [1]. They studied the effect of dust deposition on the reduction of solar intensity and the power output of the solar panel. Although the experimental procedure was very robust to understand the ramifications of dust accumulation on solar panel efficiency, the results drawn were for a specific solar panel type which was used in the laboratory.

To understand the process of dust particles accumulation on glaze surfaces at the microscopic level, Al-Hasan [2] made a theoretical analysis on the trans- 
mittance of light through a layer of sand particles accumulated on the surface of a photovoltaic panel. A mathematical relation was derived which relates transmittance coefficient to the number of sand particles deposited on the surface.

In [3] an experimental study was performed on the relation between dust accumulation and the tilt angle of the panel where horizontal panels caught the most deposition of fine and coarse particles whereas vertical panels caught the fine particles of dust only. Tilt angle effect on dust deposition has been further studied in [4] and a regression-based model of the relationship between output power and sand particle size and irradiance was derived.

In [5] performance degradation due to deposition of different types of sand particles is investigated and a theoretical model is developed that is able to simulate the dust deposition impact on the energy behavior of solar photovoltaic (PV).

To our knowledge [6] is the only reference that suggests cleaning cycles for different regions. However, the paper only provides guidelines for cleaning the panels when installed in different climatic zones and based on the weather and dust activity level. Our approach is different in that it is based on a quantitative analysis of dust and hence yields optimal results compared to the cleaning cycles suggested in [6] which are based on qualitative understanding of dust activities.

\section{Derivation of the Optimal Number of Days between Cleaning Cycles}

The effect of sand dust particles accumulation on light transmittance coefficient is investigated mathematically and experimentally in [2]. A transmittance coefficient of 0 means the light beam did not pass and that it has been completely reflected or absorbed while a coefficient of 1 means light has passed completely without attenuation. The relation between transmittance coefficient $(\tau)$ and number of particles accumulated $(n)$ has been derived as [2]

$$
\tau=1-n Q_{e} \pi r^{2}
$$

where $r$ is the radius of the sand particle and $Q_{e}$ is the particle extinction efficiency which has been assumed to be equal to 2 since the sand dust particles settle on the surface of the glass of the photovoltaic panel far away, in comparison to the size of dust particles, from where the light is detected by the photovoltaic cells. This relation is linear with transmittance decreasing with more sand dust particles settling on the surface. In [2] a comparison between this mathematical derivation and experimental observation shows good agreement for light transmittance values in the range 0.5 to 1 . For transmittance coefficients below 0.5 the relation observed starts to deviate from the linear relationship and becoming more nonlinear. However, in practice to maintain the efficiency of the photovoltaic panels, the cleaning of panels should be performed before transmittance coefficient falls to such low values. So in our derivation of the optimal solar panel cleaning cycle, the relation between efficiency and the amount of dust accumulation will be assumed to be linear without much loss of 
accuracy.

Dust accumulation on the surface of the solar panels will cause the efficiency of the solar panel to decrement from its nominal value. So

$$
\eta=\gamma \eta_{\text {nominal }}
$$

and

$$
\gamma=1-\alpha N
$$

where $\alpha$ is the average daily losses in solar conversion efficiency due to dust and $N$ is number of days between cleaning cycles. So the financial loss due to power degradation as a result of dust accumulation on the PV system for $N$ consecutive days is

$$
(1+2+3+\cdots+N) \alpha \operatorname{si} \beta
$$

where $s$ is the average sun hours per day, $i$ is the capacity of installed PV system, and $\beta$ is the price of $\mathrm{kWh}$.

So the financial loss due to power degradation as a result of dust accumulation per annum is

$$
\begin{gathered}
C_{1}=\frac{365}{N}(1+2+3+\cdots+N) \alpha \operatorname{si} \beta \\
=\frac{365}{N}(N+1) \frac{N}{2} \alpha \operatorname{si} \beta \\
=\frac{365}{2}(N+1) \alpha \operatorname{si} \beta
\end{gathered}
$$

and if $P$ is the cost of cleaning solar array, then the cost of cleaning the panels per annum is

$$
C_{2}=\frac{365}{N} P \text {. }
$$

So the total cost is

$$
\begin{gathered}
J=C_{1}+C_{2} \\
=\frac{365}{2}(N+1) \alpha \operatorname{si} \beta+\frac{365}{N} P .
\end{gathered}
$$

Finding the optimal number of days between cleaning cycles is achieved by minimizing $J$ with respect to $N$

$$
\hat{N}=\arg \min _{N} J \text {. }
$$

So

$$
\frac{\mathrm{d} J}{\mathrm{~d} N}=\frac{365 \alpha \operatorname{si} \beta}{2}-\frac{365}{N^{2}} P=0,
$$

or

$$
\hat{N}^{2}=\frac{2 P}{\alpha \operatorname{si} \beta},
$$

or 


$$
\hat{N}=\sqrt{\frac{2 P}{\alpha \operatorname{si} \beta}} .
$$

\section{Determination of Parameter Values}

\subsection{Average Daily Loss in Solar Conversion Efficiency}

The factors that affect rate of dust deposition on PV panels are the concentration of airborne dust particles, wind speed, and relative humidity. It was reported in [7] that the higher the concentration of dust particles in the air, the higher the rate of dust deposition on the PV panels. Also relative humidity is positively correlated with rate of dust deposition since the dust particles become stickier in humid weather. On the contrary, wind speed was negatively correlated with dust deposition since higher wind speed aid in the removing of dust particles from the surface of the solar panels. These three factors differ from region to region and hence will affect the average daily loss in solar conversion efficiency in the region. For example, in California the average daily loss in solar conversion efficiency was $0.051 \%$ [8]. In Santiago, Chile the values ranged from $0.14 \%$ to $0.56 \%$ depending on the season and pollution level [9]. In the middle east, the values are high as well due to dusty weather conditions. For example, in Qatar the average daily loss in solar conversion efficiency could be as high as $0.55 \%$ [7].

\subsection{Cleaning Cost}

The process of cleaning the solar array should be performed by professional cleaner. The cost of cleaning include the cost of materials used in the cleaning process plus labor cost [10]. The cost will vary from case to case depending on the soiling type and country where the PV system is installed [11]. In the middle east region, for example, the soiling of panels is mainly due to dust accumulation and hence cleaning can be performed relatively easy with basic tools, water, and some cleaning chemicals. In cases where other types of dirts exit such as bird dropping or extra pollution, the cleaning process may involve more cost and labor.

Depending on the cost of cleaning and the level of dust accumulation, the cleaning operation may be justified or it may not be justified. In a study by Tanesab et al. [12], it was found that cleaning cost of PV panels installed in Perth, Western Australia will be much higher than loss caused by dust and hence cleaning is not justified. So the system operator can rely on natural cleaning such as rain and wind to clean the panels. In another study by Stridh [13] in three locations in Europe: Murcia in spain, Munich in Germany, and Stockholm in Sweden, it was concluded that cleaning is justified in Murcia, and to some degree in Munich, but not justified for Stockholm.

\section{Results and Discussion}

The following is a hypothetical example that shows how the result of the paper 
appearing in Equation (14) can be used. The parameter values used are typical for the middle east in general. Note that the cleaning cost of the $1 \mathrm{MW}$ array which is $\$ 250$ is relatively small compared to other countries. This is due to the fact that the type of soiling predominant in the middle east is sand which does not require much material or labor in order to be cleaned.

Example 1. A $1 M W$ solar PV system is subjected to dust accumulation that causes an average daily loss in solar conversion efficiency of 0.002 . If the $P V$ system receives an average of 5 sun hours per day, the price of $1 \mathrm{kWh}$ is $\$ 0.1$, and the cost of cleaning a solar array is $\$ 250$. How often should the solar array be cleaned to maximize the gain?

$$
\hat{N}=\sqrt{\frac{2 \times 250}{0.002 \times 5 \times 1000 \times 0.1}}=\sqrt{500} \approx 22 \text { days. }
$$

Remarks:

- Our derivation is based on the assumption that dust accumulation is linearly increasing with time. However, the climatological system is more complex and the linear assumption can work most of the time as an approximation only. Two special climatological events should be observed: rainfall and sand storms. Rainfall event will aid in cleaning the solar panels while sand storms will accumulate huge amounts of dust on the panels and cleaning should be usually performed after such event. Also it should be noted that in dry regions dust removal can occur naturally when wind blows on dusty solar panels which will further aid in the cleaning of the panels. Based on these different scenarios, our result is expected to be conservative in maintaining the solar panels clean.

- To compare the result of this paper to the approach followed in the literature by the scientific community thus far [10], we find that it will take almost 22 days till the cost due to lack of energy production becomes 250 dollars. And it is at this instant when the cleaning of the panels should be performed. However, this coincidence will not necessarily hold true if dust accumulation is not a linear function of time.

- The optimal number of days between cleaning cycles depends on a number of factors;

1) $P$ : the cost of cleaning solar array in units of $\$$,

2) $\alpha$ : the average daily losses in solar conversion efficiency due to dust in units of day ${ }^{-1}$,

3) $s$ : average sun hours per day in units of hours/day,

4) $i$ : capacity of installed PV system in units of $\mathrm{kW}$,

5) $\beta$ : price of $1 \mathrm{kWh}$ of electricity in units of $\$ / \mathrm{kWh}$.

Note that the multiplication of the last four factors $(\alpha s i \beta)$ which appears in the denominator of (14) represents the decremental daily loss in revenue due to dust accumulation on the PV panels in units of \$/day/day.

- This paper is considered as first attempt toward making decisions about cleaning solar panels based on quantitative analysis. Generally these decisions 
are made based on understanding the environment in which the solar panels are installed which might not be the best decision made. We believe further studies on the effect of dust on solar panel efficiency should be performed on a region by region bases similar to the studies performed in [8] and [14] for California region.

\section{Conclusion}

From economic perspective, solar panels should be regularly cleaned to improve the efficiency and maximize gain. However, cleaning process incurs a cost and could not be performed very frequently. Here we show a mathematical result that maximizes the gain from the solar array. The main result of the paper appearing in (14) was based on minimizing the cost function (9). Adopting this cost function is the correct approach to find the optimal number of days between cleaning cycles. And it is more appropriate than the approach followed in the literature by the scientific community thus far which is based on comparing the cleaning cost to the cost due to lack of energy production due to dust, and it is at the instant when these two costs become the same the cleaning activity should be performed.

\section{References}

[1] El-Shobokshy, M.S. and Hussein, F.M. (1993) Degradation of Photovoltaic Cell Performance Due to Dust Deposition on to Its Surface. Renewable Energy, 3, 585590. https://doi.org/10.1016/0960-1481(93)90064-N

[2] Al-Hasan, A.Y. (1998) A New Correlation for Direct Beam Solar Radiation Received by Photovoltaic Panel with Sand Dust Accumulated on Its Surface. Solar Energy, 63, 323-333. https://doi.org/10.1016/S0038-092X(98)00060-7

[3] Hegazy, A.A. (2001) Effect of Dust Accumulation on Solar Transmittance through Glass Covers of Plate-Type Collectors. Renewable Energy, 22, 525-540. https://doi.org/10.1016/S0960-1481(00)00093-8

[4] Mani, F., Pulipaka, S. and Kumar, R. (2016) Characterization of Power Losses of a Soiled PV Panel in Shekhawati Region of India. Solar Energy, 131, 96-106. https://doi.org/10.1016/j.solener.2016.02.033

[5] Kaldellis, J.K. and Kapsali, M. (2011) Simulating the Dust Effect on the Energy Performance of Photovoltaic Generators Based on Experimental Measurements. Energy, 36, 5154-5161. https://doi.org/10.1016/j.energy.2011.06.018

[6] Mani, M. and Pillai, R. (2010) Impact of Dust on Solar Photovoltaic (PV) Performance: Research Status, Challenges and Recommendations. Renewable and Sustainable Energy Reviews, 14, 3124-3131. https://doi.org/10.1016/j.rser.2010.07.065

[7] Javed, W., Guo, B., Wubulikasimu, Y. and Figgis, B.W. Photovoltaic Performance Degradation Due to Soiling and Characterization of the Accumulated Dust.

[8] Mejia, F.A. and Kleissl, J. (2013) Soiling Losses for Solar Photovoltaic Systems in California. Solar Energy, 95, 357-363. https://doi.org/10.1016/j.solener.2013.06.028

[9] Urrejola, E., Antonanzas, J., Ayala, P., Salgado, M., Ramrez-Sagner, G., Corts, C., Pino, A. and Escobar, R. (2016) Effect of Soiling and Sunlight Exposure on the Performance Ratio of Photovoltaic Technologies in Santiago, Chile. Energy Conversion and Management, 114, 338-347. https://doi.org/10.1016/j.enconman.2016.02.016 
[10] Faifer, M., Lazzaroni, M. and Toscani, S. (2014) Dust Effects on the PV Plant Efficiency: A New Monitoring Strategy. Proceedings of the 20 th IMEKO TC4 International Symposium and 18th International Workshop on ADC Modelling and Testing, Benevento, 580-585.

[11] Pavan, A.M., Mellit, A. and De Pieri, D. (2011) The Effect of Soiling on Energy Production for Large-Scale Photovoltaic Plants. Solar Energy, 85, 1128-1136. https://doi.org/10.1016/j.solener.2011.03.006

[12] Tanesab, J., Parlevliet, D., Whale, J. and Urmee, T. (2016) Dust Effect and Its Economic Analysis on PV Modules Deployed in a Temperate Climate Zone. Proceedings of the 3rd International Conference on Power and Energy Systems Engineering, Kitakyushu, 65-68. https://doi.org/10.1016/j.egypro.2016.10.154

[13] Stridh, B. (2012) Economical Benefit of Cleaning of Soiling and Snow Evaluated for PV Plants at Three Locations in Europe. Proceedings of the 27 th European Photovoltaic Solar Energy Conference and Exhibition, Frankfurt, 4027-4029.

[14] Kimber, A., Mitchell, L., Nogradi, S. and Wenger, H. (2006) The Effect of Soiling on Large Grid-Connected Photovoltaic Systems in California and the Southwest Region of the United States. Proceedings of the 4th IEEE World Conference on Photovoltaic Energy Conference, Waikoloa, 2391-2395.

https://doi.org/10.1109/WCPEC.2006.279690

Submit or recommend next manuscript to SCIRP and we will provide best service for you:

Accepting pre-submission inquiries through Email, Facebook, LinkedIn, Twitter, etc. A wide selection of journals (inclusive of 9 subjects, more than 200 journals)

Providing 24-hour high-quality service

User-friendly online submission system

Fair and swift peer-review system

Efficient typesetting and proofreading procedure

Display of the result of downloads and visits, as well as the number of cited articles

Maximum dissemination of your research work

Submit your manuscript at: http://papersubmission.scirp.org/

Or contact ojee@scirp.org 